JOURNAL OF THE SOUTH AFRICAN INSTITUTION OF CIVIL ENGINEERING ISSN 1021-2019

Vol 61 No 1, March 2019, Pages 26-37, Paper 0208

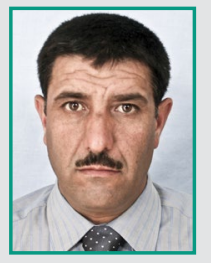

GRINI ABDELOUAHAB is a PhD student in the Laboratory of Civil and Hydraulics Engineering at the University of Guelma, Algeria. He received his BS, his Diploma of Engineering in Civil Engineering from the University of Annaba, Algeria, and his Diploma of Magister in Civil Engineering and Hydraulics from the University of Guelma,

Algeria, in 1985, 1990 and 2008 respectively. His research interests

include materials structures.

Contact details:

Laboratory of Civil and Hydraulics Engineering

University of 8 May 1945

BP 401

Guelma

Algeria

T: +21337215848

E: abdelouahab.grini@yahoo.fr

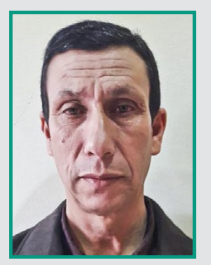

PROF BENOUIS ABDELHALIM is a researcher in the Department of Civil Engineering and a member of the team working in the Materials Division of the Laboratory of Civil and Hydraulics Engineering at the University of Guelma, Algeria. He received his BS from the University of Constantine, and his MS and PhD from ENPC-PARIS, France, in 1988, 1991 and 1995 respectively. His research interests include durability and NDT of concrete and reinforced concrete structures.

Contact details:

Laboratory of Civil and Hydraulics Engineering

University of 8 May 1945

BP 401

Guelma

Algeria

T: +21337215848

E: benouis_h@yahoo.fr

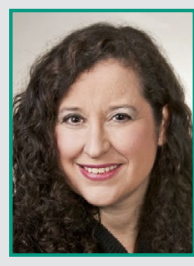

PROF DEBRA LAEFER is a Professor of Urban Informatics at New York University's Centre for Urban Science and Progress. She is also an Adjunct Faculty Member in Civil Engineering at the University College Dublin. She holds degrees from Columbia University, the University of Illinois at Urban-Champaign, and New York University.

Contact details:

Center for Urban Science and Progress and

Department of Civil and Urban Engineering

Tandon School of Engineering

New York University

370 Jay Street, 12th Floor

Brooklyn

New York 11201

United States of America

T: +16469970504

E: debra.laefer@nyu.edu

Keywords: self-consolidating concrete, ultrasonic pulse velocity, concrete segregation, sieve stability test, column test

\title{
Characterising the segregation of self-consolidating concrete using ultrasonic pulse velocity
}

\author{
G Abdelouahab, B Abdelhalim, D F Laefer
}

Segregation is the unintentional separation of the fresh components of concrete or mortar, which can have negative impacts on the mechanical, transport and durability properties of the cured product. The problem is acute in self-consolidating concrete (SCC), because of its high fluidity level. To help evaluate segregation, this paper investigates the potential of using ultrasonic pulse velocity (UPV) as a means to identify and characterise segregation in traditional and SCC mixes. Fourteen different concrete mixes were tested using standard techniques (sieve and column) in comparison with the UPV-based test proposed herein. Six of the 14 concrete mixtures were stable, as indicated by having sieve segregation indices lower than $15 \%$ and segregation resistances $(f)$ higher than $95 \%$. These six stable samples displayed UPV segregation index values $\left(f_{u}\right)$ approaching $100 \%$. The remaining samples were found to be unstable concretes with sieve segregation index values higher than $15 \%$ and resistance index values lower than $65 \%$. These concretes could also be clearly identified as unstable by a UPV segregation index lower than $80 \%$. The UPV method provides a clean, quick and easy nondestructive alternative for testing segregation of both fresh and hardened concrete.

\section{INTRODUCTION}

Segregation is the separation of the constituents of a fresh concrete or mortar. When segregation occurs in concrete, there is a concentration of coarse aggregates in some areas and fine aggregates in others. Segregation results in non-uniform concrete with non-uniform distributions of engineering properties like strength, stiffness and time-dependent deformation with respect to substandard durability and structural performance (Panesar \& Shindman 2012), which are likely to contribute to higher maintenance costs and/or a shorter life expectancy.

Segregation may occur due to a concrete's mix or its handling. For example, water quantity is known to influence the separation between mortar and aggregate (Li \& Kwan 2013). To counter this risk of impacting long-term concrete strength, water-reducing admixtures are often used to minimise the quantity of mixing water required to produce concrete of a certain workability. Unfortunately these admixtures (plasticisers and fluidisers, among others) may cause excessive bleeding or segregation (Uysal et al 2012; Hattori 1979). The problem occurs in regular concretes and those with highly cohesive concrete mixtures (Ghafoori \& Diawara 2010; Job \& Harilal 2014), such as those containing limestone filler. The problem is also a common risk in selfconsolidating concrete (SCC) (Khayat \& Guizani 1997; Bauchkar \& Chore 2014; Vakhshouri \& Nejadi 2016).

Limestone filler is frequently used in SCC technology as a means to minimise segregation (Grzeszczyk \& Podkowa 2004). The air content influences concrete bleeding, as well as segregation. Larger volumes of air decrease viscosity and influence the volume of paste available to improve the flow (Beaupre 1994; Benaicha et al 2015). Furthermore, SCC, which has gained worldwide popularity since its first introduction in 1990 (Okamura \& Ouchi 2003), is characterised by its ability to spread in place under its own weight without the need of externally applied compaction energy. The idea is that SCC is inherently better able to achieve reinforcement bar coverage and reduce honeycombing without the risk of vibrator-induced segregation. Thus, SCC can significantly improve the longterm performance of in-situ concrete [as extensively discussed elsewhere, e.g. Xie et al (2002)]. With SCC, the segregation risk stems from its generally high fluidity; typically, an SCC mix has a water-cement ratio of about 0.4 . The segregation generally occurs during placement (Khayat \& 
Feys 2010), and the resulting heterogeneities may compromise strength, deformation, and durability in those areas.

Segregation tests are usually performed on samples of fresh concrete or at the beginning of hardening (Okamura \& Ouchi 2003; Shindoh \& Matsuoka 2003; Rakesh 2015). A current test for this is the sieve stability test, which measures the portion of the fresh SCC sample passing through a $5 \mathrm{~mm}$ sieve. If the SCC has a poor resistance to segregation, it can easily pass through the sieve. Therefore, the sieved portion indicates the SCC stability - likelihood to segregate (De Schutter 2005). Another segregation test widely used with SCC is the column stability test (ASTM International 2017), in which the difference between the percentages by weight of coarse aggregate in the bottom and top sections are considered (Ambroise et al 1999; Rols et al 1999). In contrast, the column stability test involves the analysis of samples from the top and bottom parts of the column, to determine the proportion of the coarse aggregate (Cussigh et al 2003). This apparatus has been employed for over 35 years (Sidky et al 1981), evaluated in several European countries, and considered sufficiently sensitive to the variations of SCC design for widespread adoption. Finally, the penetration test, in which a cylinder of pre-specified dimensions is allowed to penetrate a fresh SCC sample, is another commonly used method. The penetration depth indicates a SCC's stability level (De Schutter 2005). These tests allow estimating concrete segregation in the material's fresh state.

There are also non-destructive testing (NDT) approaches for hardened concrete (e.g. Kumavat et al 2014; Mesbah et al 2011; Silva \& Brito 2013). Of particular relevance is the work by Breul et al (2008) who used image analysis to estimate concrete segregation on-site. As part of that work, experiments on SCC and crushed particle concrete were conducted in $16 \mathrm{~cm}$ diameter columns. Measurements were compared with results acquired on the same columns using a video-counting method. Concerning the segregation characterisation, image analysis seems well adapted and provides a fast mapping of the structure by interpolation. Gamma densitometry has also been used to evaluate segregation in SCC mixes (Schwhdenmann 2005; Li et al 2011; Kundu 2014). As many NDT methods have found application in the construction industry, intense research in this field has led to improved NDT equipment, which has made data collection quicker and easier. With proper analysis of these NDT results more is possible beyond simple quality checks, including possible prediction of important material parameters (Sanish \& Manu 2012). While effective, deployment issues remain that preclude rapid, widespread usage of these NDT techniques.

As a work-around to those challenges, the ultrasonic pulse velocity (UPV) method was introduced for both field and laboratory work and is the most widely used NDT test for the inspection and evaluation of concrete structures today. UPV is mainly deployed for the determination of the dynamic modulus of elasticity and Poisson's ratio (Huet 1982). Using UPV, Naik and Malhotra (1991), and Malhotra and Carino (1991) demonstrated that the relationship between compressive strength and pulse velocity was non-linear. They concluded that several parameters can interfere, including the composition of the concrete and its moisture content. While there are existing standards that propose correlations to overcome these difficulties (e.g. RILEM 1973; ASTM International 2009; British Standards Institute 2004), heterogeneity creates dispersions of the pulsations (Xiong et al 2011), which complicates matters, as these dispersions are caused by indirect factors such as the origin of the concrete mixture and the problems of casting in-situ (e.g. over-vibration, or placement from too high a height). However, early work in applying UPV to concrete, such as the work by Zülfü et al (2008) on the correlation between ultrasonic velocity and compressive strength, by Abdelhalim and Abdelouahab (2011) on the estimation of a concrete's porosity, by Kumavat et al (2014) on general condition assessment, and by Abdelouahab and Abdelhalim (2016) on the segregation of ordinary concrete, show the potential of the technique, but do not assess its robustness when applied to a variety of SCC mixes, which is the focus of the new research presented herein.

Specifically, the aforementioned initial efforts indicated UPV as a promising technology for studying concrete segregation, a topic to which UPV has not been regularly employed. The opportunity to use it arises from the heterogeneity in concrete pulse dispersions (Silva \& Brito
2013; Kundu 2014) that can be caused by indirect factors, such as the origin of the aggregates, the mixture's ingredients, and problems of consolidation (vibration) during concrete placement. The work herein proposes that concrete density variation through the height of an element can be determined by UPV, noting that the elastic modulus can be influenced by the large aggregates in concrete versus only the small aggregates in the mortar. Thus, the objective of this experimental study is to analyse correlations between various segregation indices and UPV outputs in SCC mixes to assess the viability of UPV for on-site segregation evaluation. Ultimately, this work aims to propose a rapid, non-destructive method of characterising segregation in fresh SCC mixes.

\section{RESEARCH SIGNIFICANCE AND EXPERIMENTAL PROCEDURE}

This paper presents comparative experimental work on 14 different self-compacting concrete samples using two standard techniques (sieve and column) in comparison to the herein proposed UPV-based test using a testing procedure introduced by Abdelouahab and Abdelhalim (2016). Correlations were performed with respect to various segregation indices to test whether the UPV method is efficient and reliable compared to traditional methods. The UPV was used to determine differences between the samples' top and bottom sections as cast. The study also concerns the exploration of correlations between the different parameters studied amongst selfcompacting concrete samples.

To understand the potential applicability and reliability of UPV to identify segregation problems in SCC mixes, an experimental programme was devised. The scope of that work involved the following: sieve stability tests, as described by EFNARC (2005), column stability tests (e.g. Cussigh et al 2003; British Standards Institute 1986; Sonebi 2005; Rooney \& Bartos 2001), and UPV testing (newly developed). All are described below.

\section{Sieve stability test as per \\ EN 12350-11 (EN 2010)}

Principle: The test aims to investigate the resistance of an SCC mix to segregation by allowing a $10 \mathrm{~L}$ sample to undergo static segregation for 15 minutes (in a bucket). Then the top layer of the sample $(4.8 \mathrm{~kg} \pm 0.2)$ is poured into a $5 \mathrm{~mm}$ 
sieve. Some mortar then passes through the sieve. An index $\pi$ (the mass percentage of the sample passing through the sieve) is determined using Equation 1 and expressed in terms of the nearest $1 \%$ (AFGC 2000). The amount of material passing through the sieve indicates the propensity towards segregation.

$\pi=\frac{M_{c S}}{M_{c}} \cdot 100$

Where:

$M_{c s}=$ mass of concrete collected through the $5 \mathrm{~mm}$ sieve opening size

$M_{c}=$ initial mass of the top layer.

\section{Column stability test}

Principle: In this test, fresh concrete is placed in a tube (cross-section = $100 \times 100 \mathrm{~mm}$, height $=500 \mathrm{~mm}$ ). Concrete is then taken from the top $(A=100.100 .100 \mathrm{~mm})$ and bottom $(B=100.100 .100 \mathrm{~mm})$ parts of the column. After being washed through a sieve, samples are analysed to determine the proportion of coarse aggregate. Only aggregates greater than $5 \mathrm{~mm}$ in size are analysed. An index $f$ is determined as per Equation 2 to an accuracy of $\pm 1 \%$.

$f=\frac{M_{\alpha}{ }^{A}}{M_{\alpha}{ }^{B}} \cdot 100$

Where:

$M_{\alpha}{ }^{A}=$ coarse aggregate mass in the top part (retained on $5 \mathrm{~mm}$ sieve opening size)

$M_{\alpha}{ }^{B}=$ coarse aggregate mass in the bottom part (retained on $5 \mathrm{~mm}$ sieve opening size).

\section{Proceedings ultrasonic test}

Principle: Based on the techniques of segregation characterisation used in the column stability test (British Standards Institute 1986), UPV can be used for material in its fresh state or at the beginning of hardening (Hamidian et al 2012) to determine an ultrasonic segregation index $f_{u}$ and to establish correlations between the last index, the sieve segregation index $\pi$, and the segregation resistance $f$. The ultrasonic coefficient of segregation resistance will be proposed as per Equation 3 to an accuracy of $\pm 1 \%$.

$f_{u}=\frac{V_{A}}{V_{B}} \cdot 100$

(a)
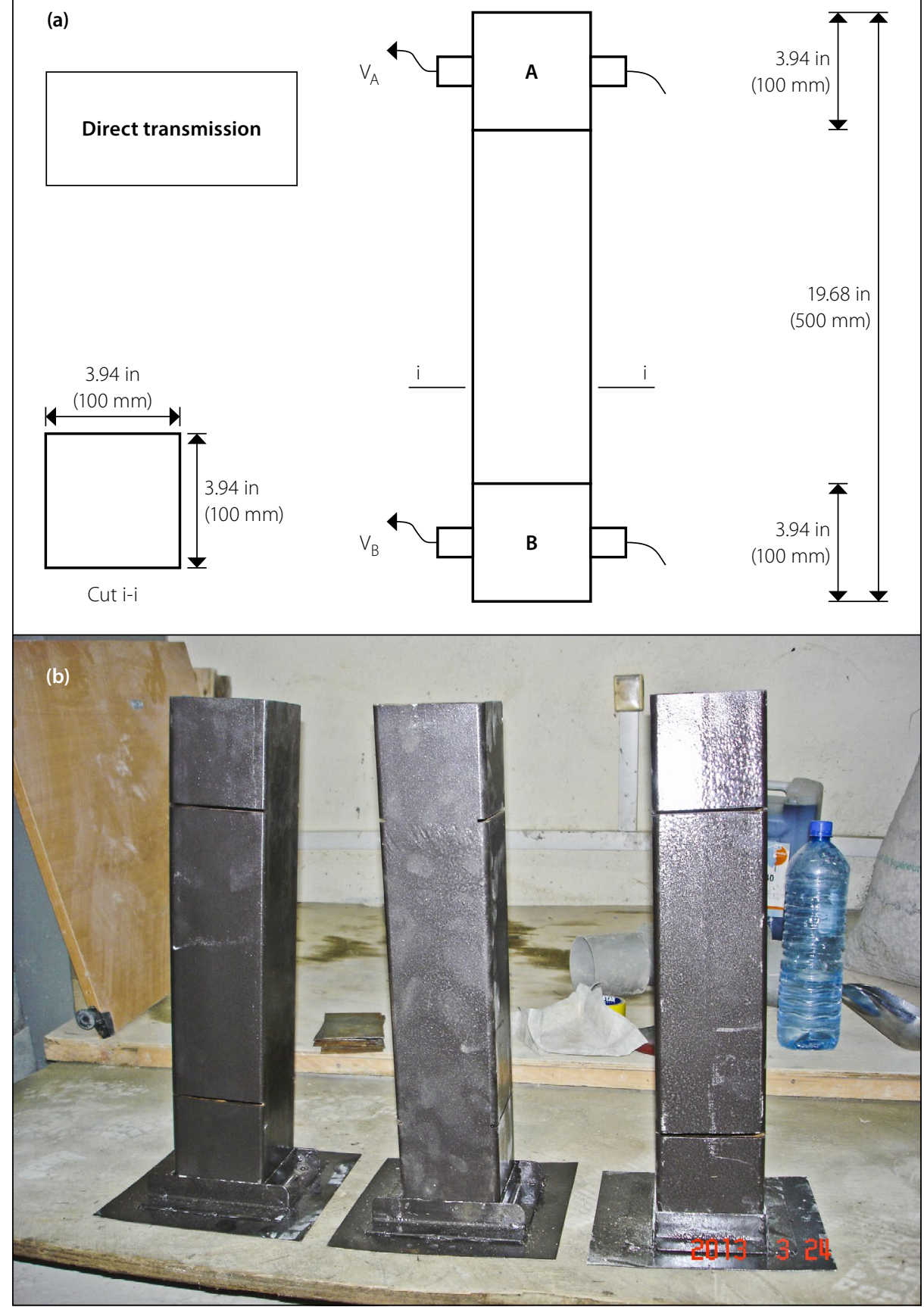

Figure 1 Measurement procedure: segregation resistance by ultrasound pulse velocity: (a) velocity propagation on Parts A and B, (b) tube steel moulds

Where:

$V_{A}=V_{f A}-V_{e A}:$ Propagation velocity ratio in the top section $(A)$ between the filled mould and the empty mould

$V_{B}=V_{f B}-V_{e B}$ : Propagation velocity ratio in the bottom section $(B)$ between the filled mould and the empty mould, respectively (Figure 1).

$V_{f}=$ is the propagation velocity in a zone of the filled mould

$V_{e}=$ is the propagation velocity in a zone of the empty mould.

The pulse velocity is known to be affected significantly by the type and amount of aggregate (Bullock \& Whitehurst 1959; Jones 1962; Popovics et al 1990).
In general, the pulse velocity of cement paste is lower than that of aggregate. According to several studies (e.g. Bullock \& Whitehurst 1959; Kaplan 1959; Jones 1962), at the same strength level concretes with higher aggregate content give higher pulse velocities.

The samples were tested using ultrasound for determination of the velocities of the longitudinal ultrasonic waves. UPV tests were conducted for each sample using a portable ultrasound model E58 and pulses with a $54 \mathrm{kHz}$ frequency (Figure 2).

An average of three readings per sample was taken, as reported herein. The actual testing procedures are described 
Table 1 Physical and chemical properties of the materials used

\begin{tabular}{|c|c|c|c|}
\hline Factor & Cement* & Limestone filler* & Superplasticiser* \\
\hline $\mathrm{CaCO}_{3}(\%)$ & - & 98.00 & - \\
\hline $\mathrm{CaO}(\%)$ & $55-65$ & 56.03 & - \\
\hline $\mathrm{SiO}_{2}(\%)$ & $22-28$ & 0.04 & - \\
\hline $\mathrm{AL}_{2} \mathrm{O}_{3}(\%)$ & $5-6$ & 0.08 & - \\
\hline $\mathrm{Fe}_{2} \mathrm{O}_{3}(\%)$ & $3-3.6$ & 0.02 & - \\
\hline $\mathrm{MgO}(\%)$ & $1-2$ & 0.17 & - \\
\hline $\mathrm{K}_{2} \mathrm{O}(\%)$ & $0.3-0.6$ & 0.02 & - \\
\hline $\mathrm{NaO}_{2}(\%)$ & $0.1-0.16$ & 0.05 & - \\
\hline $\mathrm{SO}_{3}(\%)$ & $1.8-2.5$ & 0.0021 & - \\
\hline $\mathrm{CaOL}(\%)$ & $0.8-1.8$ & - & - \\
\hline $\mathrm{Cl}-$ & $0-0.01$ & 0.0033 & $<1$ \\
\hline Loss on ignition (\%) & - & 43 & - \\
\hline Density (kg/l) & 3.15 & 2.7 & 1.2 \\
\hline Blaine $\left(\mathrm{cm}^{2} / \mathrm{g}\right)$ & $3300-4000$ & - & - \\
\hline $\mathrm{pH}$ & - & 9 & 8.2 \\
\hline Beginning of setting time $(\mathrm{mn})$ & $\geq 60$ & - & - \\
\hline End of setting time $(\mathrm{mn})$ & $150-250$ & - & - \\
\hline
\end{tabular}

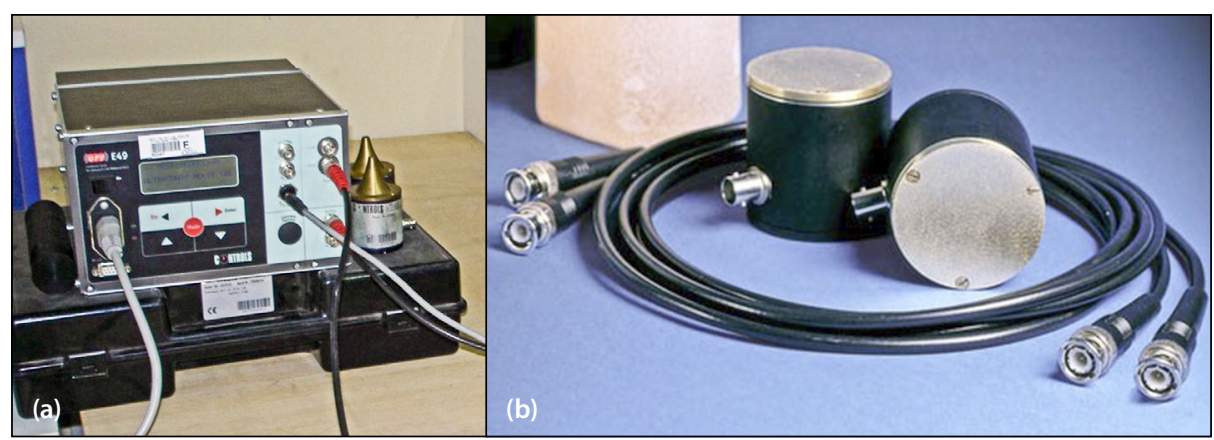

Figure 2 The UPV equipment used: (a) ultrasonic device, (b) transducers which used $54 \mathrm{kHz}$

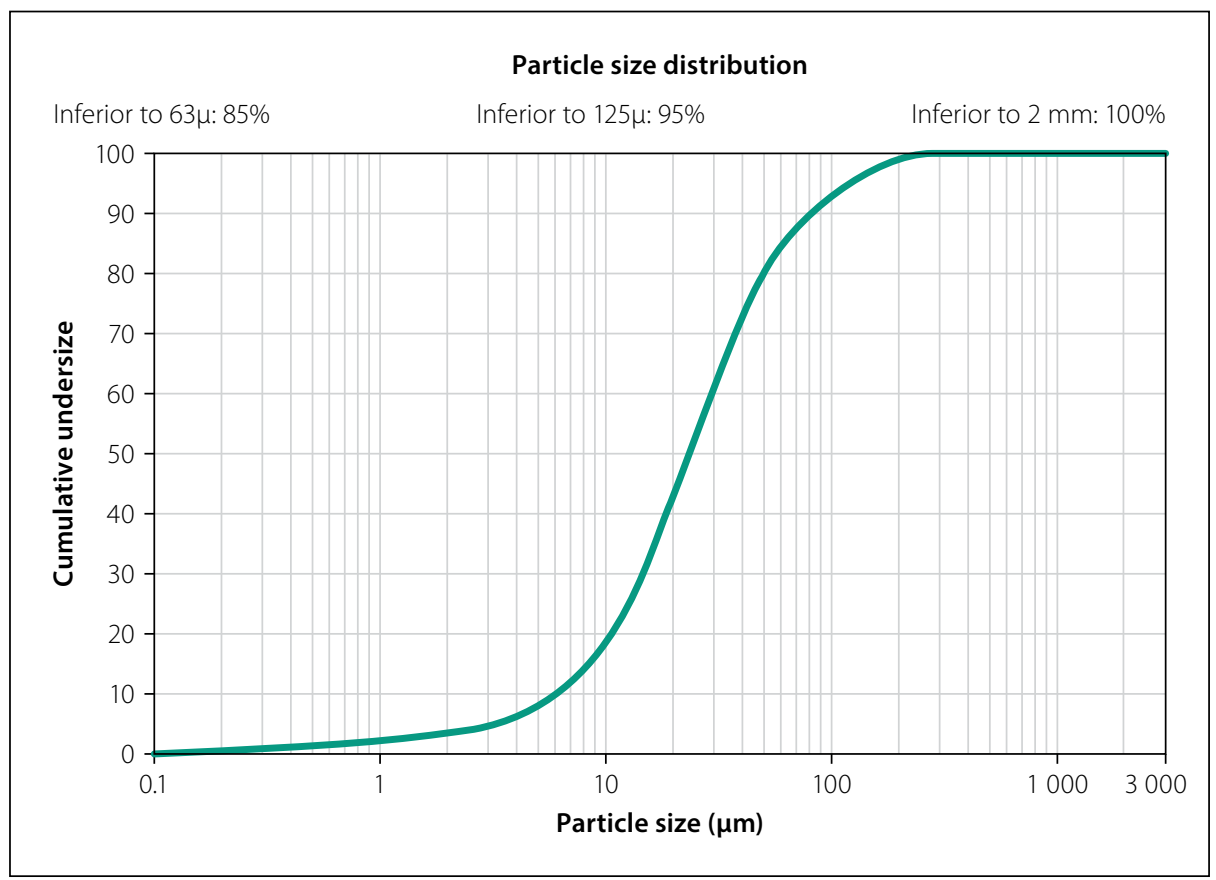

Figure 3 Particle size distribution of limestone of filler (permission for re-use granted by Entreprise Nationale des Granulats, Unité El Khroub) in ISO1920-7 (ISO 2004). The principle of the test is that the pulse of the longitudinal vibrations is produced by an electro-acoustical transducer (transmitter). After traversing a known path length in the concrete, the pulse vibrations were converted into electrical signals by a second transducer "receiver" (IAEA 2002). Electronic timing circuits enable the transit time of the pulse to be measured and, thus, the velocity of the pulse to be calculated. This involved developing a series of mixes (as will subsequently be described) and applying two common tests (sieve and column), as well as the proposed UPV method. For each sample, a segregation index $f$ was generated according to the three procedures. The UPV test method and the column test method measured both the segregation and plastic sedimentation; plastic sedimentation is affected by segregation, bleeding and setting time. In contrast, the sieve stability method only measured segregation.

\section{Materials}

The experimental materials were sourced locally in Algeria, including an ordinary Portland cement (CEM II-A, 42.50), a limestone filler (a 0/80 $\mu \mathrm{m})$ to modify the viscosity, and a polycarboxylate type based superplasticiser. The crushed fine aggregates had a maximum grain size of $5 \mathrm{~mm}$, a fineness modulus of 2.56 , and a specific gravity of 2.53 . The coarse aggregates had a maximum size of $15 \mathrm{~mm}$ and a specific gravity of 2.67. The chemical composition of the local Portland cement and mineral admixtures are given in Table 1 (the values are from manufacturers), along with a few performance characteristics of various components. The particle size distributions of the limestone filler, fine aggregate and coarse aggregate are shown in Figures 3 and 4 .

\section{Mixture proportions}

This work aims to assess the applicability of ultrasonic velocity measurements to various SCC mixtures to determine segregation. As such, the concrete formulations were based on methods described by Okamura and Ouchi (2003) and Bensebti (2008). In the research herein, the proportion of coarse aggregate was fixed at $50 \%$ with sand as $40 \%$ of the total volume of the mixture (cement, sand, filler and water). Ideally, the volume of the SCC paste should allow the concrete to flow, while minimising the cost of the 


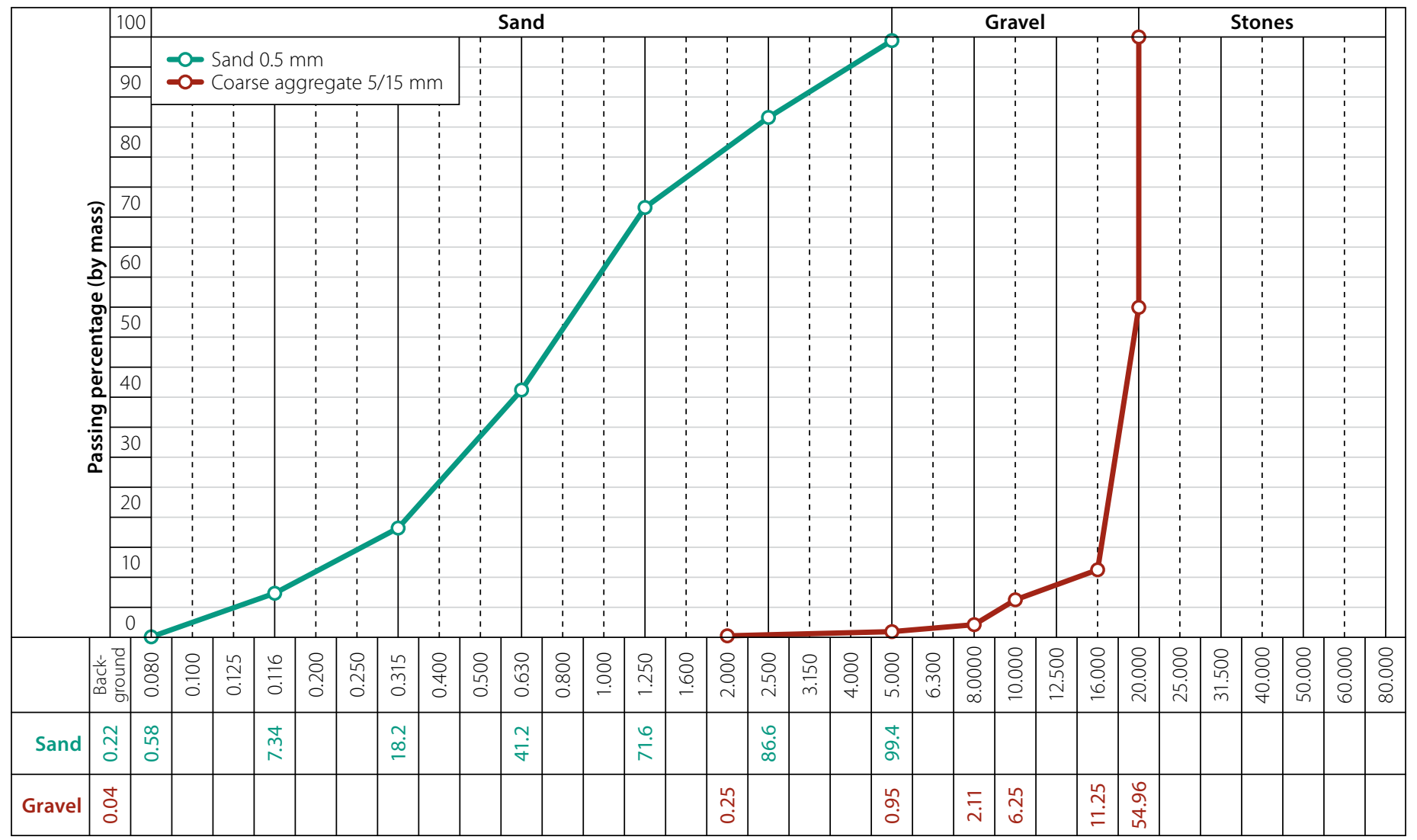

Figure 4 Particle size distribution of fine and coarse aggregate (permission for re-use granted by the Laboratory of Civil and Hydraulic Engineering at Guelma University)

raw materials. The compositions of the 14 mixtures tested are presented in Table 2 . In all of the mixes, the binder quantity was held constant, and the ratios of the other constituents were varied: filler (0\% to $20 \%)$, superplasticiser (1.7\% to $2 \%$ ) and water (32\% to $48 \%)$. The 14 mixes represented two groups of material: a set of unstable mixes (C1-C8) likely to segregate (with sieve segregation index values higher than $15 \%$ and resistance index values lower than 65\%) and a set of stable mixes (C9-C14) unlikely to segregate. Within each group, the percentage of filler to binder was changed starting with $0 \%$ and eventually reaching $20 \%$.

\section{Table 2 Mix proportions}

\begin{tabular}{|c|c|c|c|c|c|c|c|c|c|}
\hline \multirow[b]{2}{*}{ Concrete } & \multicolumn{9}{|c|}{ Proportions in $\mathrm{kg} / \mathrm{m}^{3}$} \\
\hline & $\begin{array}{c}\text { Gravel } \\
(5-15 \mathrm{~mm})\end{array}$ & $\begin{array}{c}\text { Sand } \\
(0-5 \mathrm{~mm})\end{array}$ & $\begin{array}{l}\text { Cement } \\
\text { (C) }\end{array}$ & $\begin{array}{l}\text { Fillers } \\
\text { (F) }\end{array}$ & $\begin{array}{l}\text { Water } \\
\text { (W) }\end{array}$ & $\begin{array}{l}\text { Super- } \\
\text { plasticiser } \\
\text { (Sp) }\end{array}$ & $\begin{array}{c}a^{*}=F / B \\
(\%)\end{array}$ & $\begin{array}{c}b^{*}=\text { SP/B } \\
(\%)\end{array}$ & $\begin{array}{c}d^{*}=W / B \\
(\%)\end{array}$ \\
\hline C01 & 775 & 736 & 495 & 0.0 & 237.8 & 9.91 & 0.00 & 2.00 & 48 \\
\hline $\mathrm{CO2}$ & 775 & 736 & 477 & 24 & 235.2 & 9.71 & 4.76 & 1.94 & 47 \\
\hline $\mathrm{CO3}$ & 775 & 736 & 460 & 46 & 232.5 & 9.50 & 9.09 & 1.88 & 46 \\
\hline CO4 & 775 & 736 & 457 & 55 & 230.2 & 9.49 & 10.71 & 1.86 & 45 \\
\hline C05 & 775 & 736 & 454 & 64 & 227.8 & 9.48 & 12.28 & 1.83 & 44 \\
\hline C06 & 775 & 736 & 452 & 72 & 225.3 & 9.47 & 13.79 & 1.81 & 43 \\
\hline $\mathrm{CO}$ & 775 & 736 & 450 & 81 & 222.8 & 9.46 & 15.25 & 1.78 & 42 \\
\hline C08 & 775 & 736 & 429 & 107 & 219.8 & 9.11 & 20.00 & 1.70 & 41 \\
\hline C09 & 775 & 736 & 618 & 0.0 & 198.0 & 12.35 & 0.00 & 2.00 & 32 \\
\hline $\mathrm{C} 10$ & 775 & 736 & 577 & 29 & 200.0 & 11.76 & 4.76 & 1.94 & 33 \\
\hline $\mathrm{C} 11$ & 775 & 736 & 550 & 55 & 200.0 & 11.37 & 9.09 & 1.88 & 33 \\
\hline $\mathrm{C} 12$ & 775 & 736 & 528 & 84 & 196.0 & 11.06 & 13.79 & 1.81 & 32 \\
\hline $\mathrm{C} 13$ & 775 & 736 & 509 & 102 & 195.0 & 10.75 & 16.67 & 1.76 & 32 \\
\hline $\mathrm{C} 14$ & 775 & 736 & 488 & 122 & 195.0 & 10.36 & 20.00 & 1.70 & 33 \\
\hline
\end{tabular}

* [B; binder, $(a=F / B)$; limestone filler-to-binder ratio, $(b=S p / B)$; superplasticiser-to-binder ratio, ( $d=W / B)$; water-to-binder ratio] 


\section{Testing procedure}

Firstly, a perforated plate sieve with square holes of $5 \mathrm{~mm}$, a frame diameter of $300 \mathrm{~mm}$, and a height of $40 \mathrm{~mm}$ were used for testing (ISO 2004). The test column used to evaluate the segregation resistance was a steel mould measuring $500 \mathrm{~mm}$ in height and $100 \times 100 \mathrm{~mm}$ in cross-section. This mould was also used for the UPV test, where transducers were attached to the outside of the steel column, which were coupled to the surface through a suitable medium (e.g. grease), at each of the two ends (Figure 1) (Kumavat et al 2014). These procedures were applied to the mixtures listed in Table 2. The temperature during mixing and testing ranged from $18^{\circ} \mathrm{C}$ to $22^{\circ} \mathrm{C}$.

The experimental work conducted on the 14 mixes in Table 2 involved the following:

- Sieving method using Equation 1

- Column method using Equation 2

- Ultrasonic velocities method proposed using Equation 3

\section{Characterisation of fresh concretes} SCC mixes require validation through all three of these tests (for "ordinary" concrete only one is required). A spread ranging between $640 \mathrm{~mm}$ and $720 \mathrm{~mm}$, an $\mathrm{H} 2 / \mathrm{H} 1$ ratio higher than 0.80 for the "L" box, and a sieve segregation index $\pi$ ranging between 0 and $15 \%$ are all necessary. Additionally, the tests should be conducted in-situ, as well as in the laboratory.

\section{Characterisation of segregation}

At the end of mixing, tests are immediately conducted to assess resistance to segregation. This was done firstly by the sieve segregation test, secondarily by UPV measurement and, finally, by the column test.

For the column test, several segregation characterisation techniques have been reported in the literature (Kumavat et al 2014; Lowke et al 2003). In this case, the fresh concrete was placed in a tube (cross-section $100 \times 100 \mathrm{~mm}$, height $500 \mathrm{~mm}$ ). The concrete was taken from the top $(\mathrm{A}=100 \times 100 \times 100 \mathrm{~mm})$ and bottom $(B=100 \times 100 \times 100 \mathrm{~mm})$ parts of the column. After being washed through a sieve, the samples were analysed to determine the proportion of coarse materials within the aggregate. Segregation resistance $f$ was expressed as the ratio between the coarse aggregate mass in the top part and the coarse aggregate mass in the bottom part where:

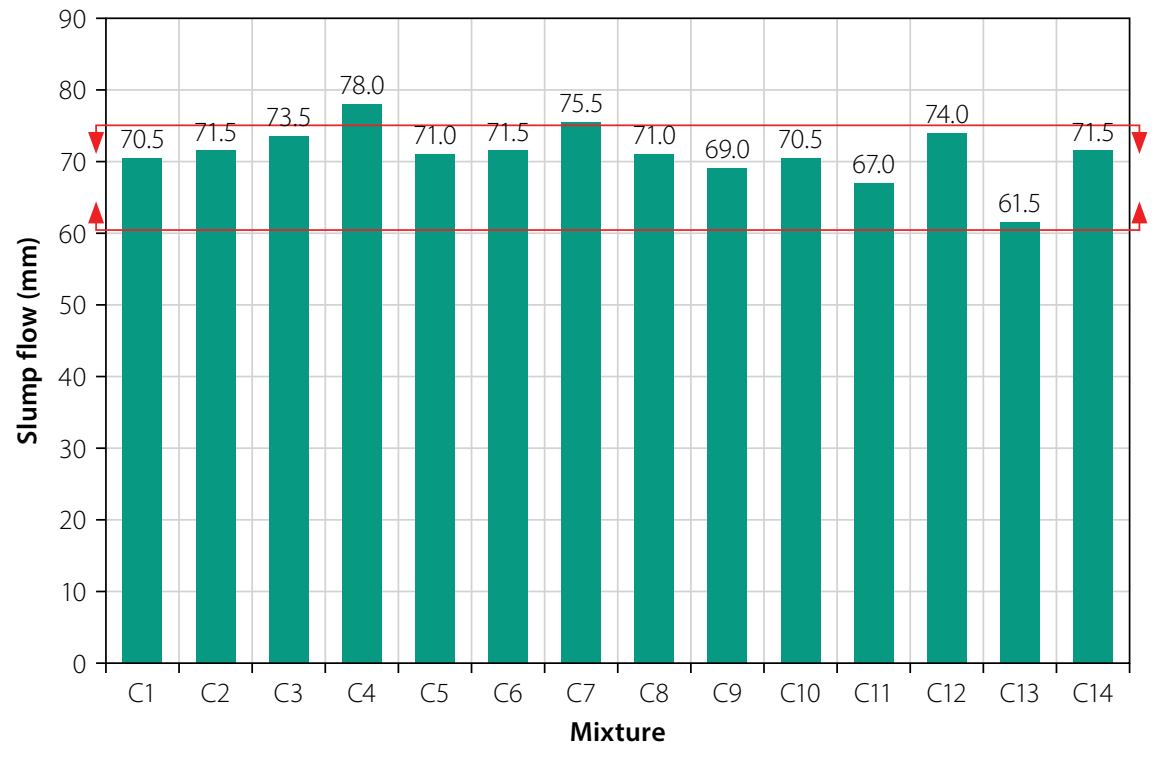

Figure 5 Slump flow (Sf) for all SCC mixes

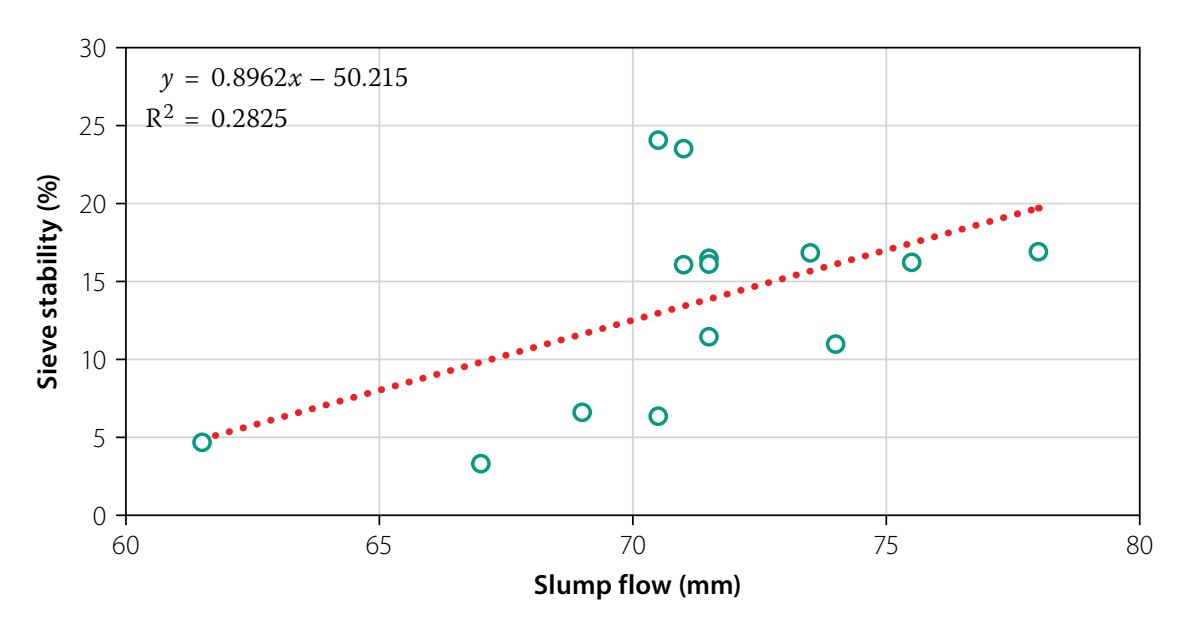

Figure 6 Sieve stability vs slump flow

$f>0.95$ corresponds to a good segregation resistance

- $f<0.90$ corresponds to a tendency towards segregation.

In the tests herein, tube forms were also used to determine a similar coefficient based on UPV $\left(f_{u}\right)$.

\section{Ultrasonic velocity measurements}

The ultrasonic coefficient of segregation resistance proposed will be as per Equation 3. In the temperature range from $22^{\circ} \mathrm{C} \pm 2^{\circ} \mathrm{C}$ and one hour after casting, the measurement consisted of determining the propagation time of sound waves through the fresh concrete at the upper (A) and lower (B) parts of the samples (Figure 1a, b). For this, a pair of transducers was used (Figure 2b), one serving as a source (emitter) and the other as a receiver. Guided by EN 12504-4 (EN 2010), direct transmission mode was conducted after casting. The process used a sensor and a nominal frequency transmitter of $54 \mathrm{kHz}$ (Figure 2a), both standard in the industry. This nominal frequency limited the depth of propagation and the minimum thickness of concrete that could be probed.

\section{EXPERIMENTAL RESULTS AND DISCUSSION}

The data on the slump flow test are given in Figure 5. Slump flow test results differed slightly from the allowable range; specifically, EFNARC (2005) suggested a slump flow value ranging from $600-750 \mathrm{~mm}$ for a concrete to be an SCC. At more than 750 $\mathrm{mm}$, the concrete might segregate, and at less than $600 \mathrm{~mm}$, the concrete might have insufficient flow to pass though highly congested reinforcement. All the concretes studied herein had a slump flow higher 
than $600 \mathrm{~mm}$. Thus, these concretes present an acceptable fluidity with no blockage risk, and conducting L-box tests to check the passing ability of the SCC was not necessary. However, when the sieve stability is between 15\% and 30\% (Figure 6), the stability is considered critical, and the specific testing of segregation is necessary (RILEM 1973; ASTM International 2009; Sonebi 2005; AFGC 2000). The tests of self-compacting practised do not have any obvious relationship between them (Figure 6); they are not redundant, but complementary to one another and highlight different aspects of self-compacting. So practising only the on-site slump test is not indicative of an SCC (Mouret et al 2003). Daczko (2002) compared some mixtures with the same fluidity and obtained different levels of stability.

The amalgamated results for each of the three samples for the 14 mixes are presented for the UPV testing (Table 3), the column testing (Table 4), and the sieve testing (Table 5). Results of the ultrasonic segregation index are expressed as the ultrasonic velocity ratio of the upper part A to that of the lower part B. Tables 3-5 clearly show a division between the unstable and stable mixes (C1-C8 vs C9-C14). The results of the UPV test can be used to assess the segregation resistance and to control the quality of concrete products, as will be further discussed in the section below.

\section{Discussion}

As described in the results, the tests were only done on fresh mixes. As was noted, the first eight concrete mixes $(\mathrm{C} 1-\mathrm{C} 8)$ were unstable, while the subsequent six mixes (C9-C14) were stable $(60 \mathrm{~mm}>S f$ $<75 \mathrm{~mm}, \pi<15 \%$ and $f<95 \%$ following this $\left.f_{u}<98 \%\right)$. Each of the three testing methods confirmed the characterisation.

The UPV remained almost constant in the case of the stable mixes (C9-C14) (Table 3). For these concretes, the average standard deviation $\bar{\sigma}$ was 6.01 $\mathrm{m} / \mathrm{s}$, with a minimum of $0.7 \mathrm{~m} / \mathrm{s}$ and a maximum of $17 \mathrm{~m} / \mathrm{s}$. For the unstable concretes $(\mathrm{C} 1-\mathrm{C} 8)$, the average standard deviation $\bar{\sigma}$ was $215.0 \mathrm{~m} / \mathrm{s}$, and ranged from a minimum of $157.7 \mathrm{~m} / \mathrm{s}$ to a maximum of $285.7 \mathrm{~m} / \mathrm{s}$.

Similarly, the column test (Table 4) demonstrated that the coarse aggregate mass remained almost constant in the stable cases (C9-C14). For these concretes, the average standard deviation $\bar{\sigma}$
Table 3 Ultrasonic testing results

\begin{tabular}{|c|c|c|c|}
\hline \multirow{2}{*}{ Mixture } & \multicolumn{3}{|c|}{$\ln \mathrm{m} / \mathrm{s}$} \\
\hline & Side A & Side B & $\sigma^{*}$ \\
\hline $\mathrm{C} 1$ & 2198 & 2421 & 157.7 \\
\hline$C 2$ & 2229 & 2515 & 202.2 \\
\hline C3 & 2183 & 2533 & 247.5 \\
\hline C4 & 2232 & 2520 & 203.6 \\
\hline C5 & 2239 & 2493 & 179.6 \\
\hline C6 & 2165 & 2514 & 246.8 \\
\hline$C 7$ & 2166 & 2444 & 196.6 \\
\hline $\mathrm{C} 8$ & 2132 & 2536 & 285.7 \\
\hline C9 & 2560 & 2565 & 3.5 \\
\hline $\mathrm{C} 10$ & 2567 & 2580 & 9.2 \\
\hline C11 & 2591 & 2597 & 4.2 \\
\hline $\mathrm{C} 12$ & 2560 & 2561 & 0.7 \\
\hline $\mathrm{C} 13$ & 2559 & 2561 & 1.4 \\
\hline $\mathrm{C} 14$ & 2533 & 2557 & 17.0 \\
\hline
\end{tabular}

Table 4 Column testing results

\begin{tabular}{|c|c|c|c|}
\hline \multirow{2}{*}{ Mixture } & \multicolumn{3}{|c|}{ In kg } \\
\hline & $\begin{array}{c}\text { Top } \\
\text { part A }\end{array}$ & $\begin{array}{c}\text { Top } \\
\text { part B }\end{array}$ & $\boldsymbol{\sigma}$ \\
\hline $\mathrm{C} 1$ & 0.46 & 0.78 & 0.23 \\
\hline C2 & 0.51 & 0.80 & 0.21 \\
\hline C3 & 0.43 & 0.80 & 0.26 \\
\hline C4 & 0.40 & 0.75 & 0.25 \\
\hline $\mathrm{C} 5$ & 0.44 & 0.95 & 0.36 \\
\hline C6 & 0.55 & 0.96 & 0.29 \\
\hline$C 7$ & 0.49 & 0.86 & 0.26 \\
\hline $\mathrm{C} 8$ & 0.40 & 0.84 & 0.31 \\
\hline C9 & 0.71 & 0.74 & 0.02 \\
\hline $\mathrm{C} 10$ & 0.79 & 0.83 & 0.03 \\
\hline $\mathrm{C} 11$ & 0.75 & 0.79 & 0.03 \\
\hline $\mathrm{C} 12$ & 0.85 & 0.89 & 0.03 \\
\hline $\mathrm{C} 13$ & 0.71 & 0.73 & 0.02 \\
\hline C14 & 0.71 & 0.74 & 0.02 \\
\hline
\end{tabular}

Table 5 Summary of test results: ultrasonic, column and sieve coefficients

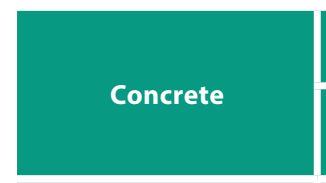

UPV coefficient

$f_{u}=$ VA/VB
$(\%)$

$90.80 \pm 3.5$

\begin{tabular}{|c|}
$\mathrm{C} 1$ \\
$\mathrm{C2}$ \\
$\mathrm{C3}$ \\
\hline
\end{tabular}

C4

C5

C6

C7

C8

C9

C10

C11

C12

C13

C14

\begin{tabular}{|c|c|}
\hline $90.80 \pm 3.5$ \\
\hline $90.70 \pm 0.4$ \\
\hline $88.20 \pm 1.8$ \\
\hline $88.60 \pm 0.8$ \\
\hline $89.50 \pm 0.0$ \\
\hline $87.20 \pm 1.2$ \\
\hline $87.20 \pm 2.3$ \\
\hline $84.10 \pm 0.3$ \\
\hline $99.80 \pm 0.0$ \\
\hline $99.50 \pm 0.3$ \\
\hline $99.80 \pm 0.2$ \\
\hline $99.90 \pm 0.2$ \\
\hline 9
\end{tabular}
Column coefficient

$f=A / B$
$(\%)$

Sieve coefficient

$\pi$
$(\%)$

$58.30 \pm 0.1$

24.08

$64.30 \pm 4.3$

$53.60 \pm 5.1$

$52.00 \pm 4.2$

$46.10 \pm 4.6$

$58.50 \pm 3.8$

$57.40 \pm 1.8$

$47.70 \pm 2.8$

23.53

$95.30 \pm 0.7$

06.60

$95.20 \pm 0.2$

$95.10 \pm 0.5$

06.35

03.30

$95.10 \pm 2.2$

08.90

$96.40 \pm 1.6$

$95.30 \pm 2.5$

04.67

11.45 


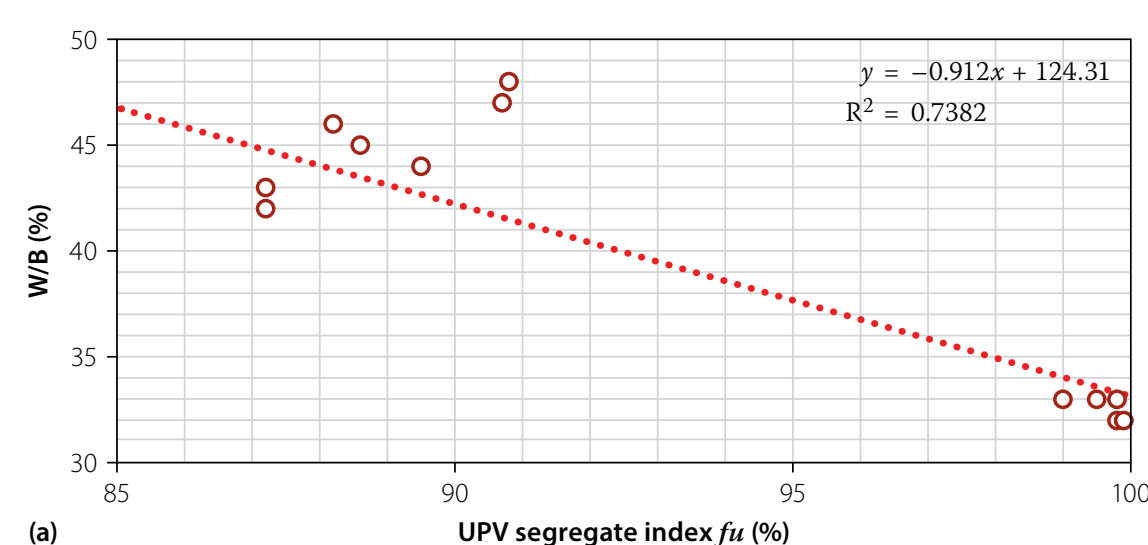

(a)

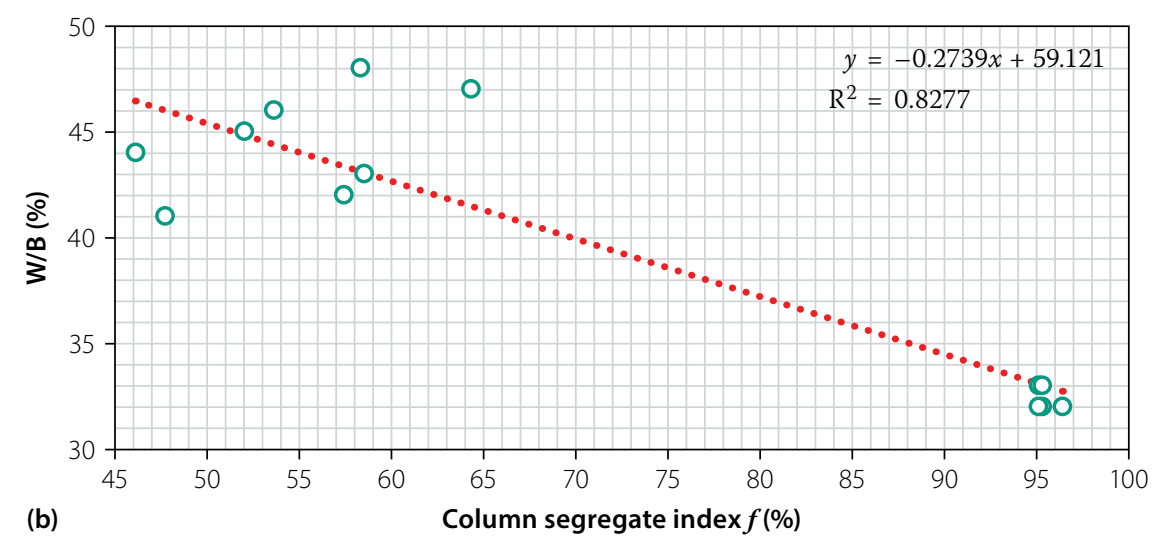

(b)

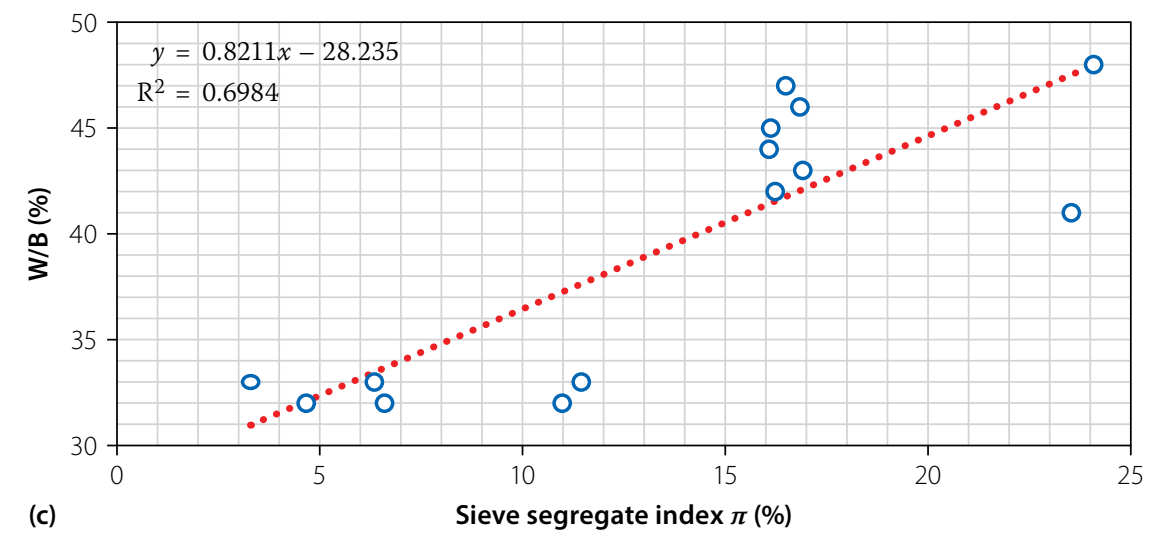

Figure 7 (a) UPV segregation index test vs ratio of water-to-binder, (b) column segregation index test vs ratio of water-to-binder, (c) sieve segregation index test vs ratio of water-tobinder, for all SCC mixes

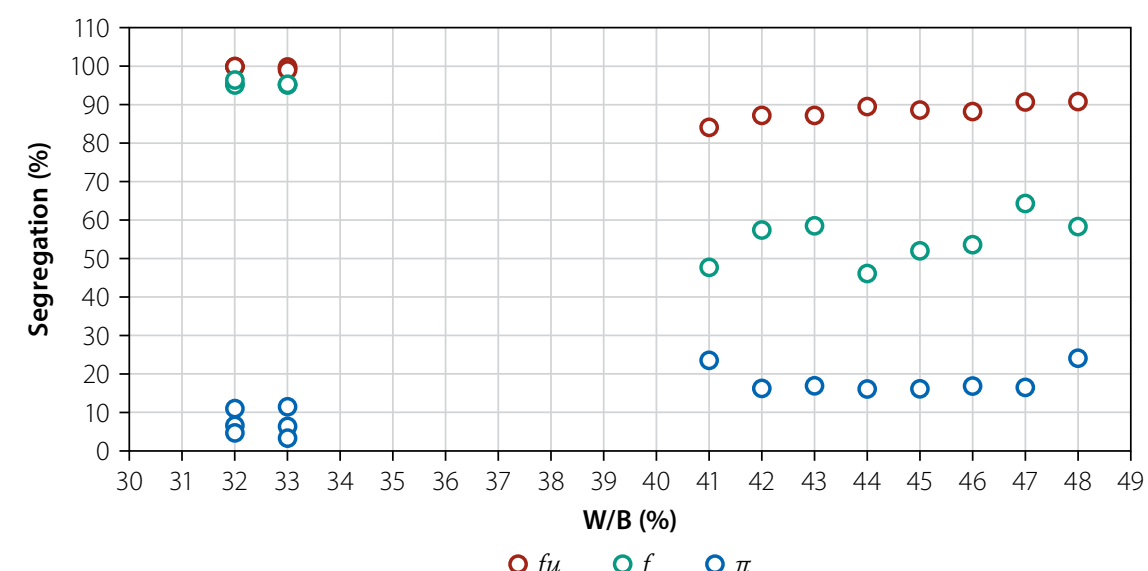

Figure 8 Evolution of the segregation index $\left(f_{u^{\prime}}, f\right.$ and $\left.\pi\right)$ with W/B ratio was $0.025 \mathrm{~kg}$ and ranged only from $0.02 \mathrm{~kg}$ to $0.03 \mathrm{~kg}$. For the unstable concretes $(\mathrm{C} 1-\mathrm{C} 8)$, the average standard deviation $\bar{\sigma}$ was an order of magnitude higher at $0.27 \mathrm{~kg}$ and ranged from $0.21 \mathrm{~kg}$ to $0.36 \mathrm{~kg}$.

In the sieve test, results (Table 5) for C9-C14 were stable with sieve segregation indices lower than $15 \%$ and resistance stability indices higher than $95 \%$. Furthermore, the coefficients of segregation resistance remained almost constant in the stable cases (C9-C14). Each of the mixes $\mathrm{C} 1-\mathrm{C} 8$ was shown to be unstable, with a sieve segregation index exceeding $15 \%$. The average standard deviation $\bar{\sigma}$ was $18.28 \%$, with a minimum of $16.08 \%$ and a maximum of $24.08 \%$. For the stable concretes (C9-C14), the average standard deviation $\bar{\sigma}$ was $7.22 \%$ and ranged from $3.3 \%$ to $11.45 \%$.

In the case of the stable mixes (C9-C14) the variation between their values did not exceed $0.9 \%$ for UPV $[(\mathrm{C} 13=99.90)-(\mathrm{C} 14=99.00)], 1.30 \%$ for the column test $[(\mathrm{C} 13=96.40)-$ $(\mathrm{C} 11=95.10)]$ and $8.15 \%$ for the sieve test $[(\mathrm{C} 14=11.45)-(\mathrm{C} 11=3.30)]$, respectively. Based on the stability test results, samples C9-C14 can be considered highly satisfactory compared to other concretes, with respect to their stability. Notably, the stable mixes C9-C14 presented an ultrasonic index of segregation approaching 100\% (Table 5).

Figure 7 presents the variations of the water-to-binder ratio (W/B) versus the segregation level obtained for the three segregation tests for all mixes. In general, the increase in W/B led to a decrease of the UPV and column values and an increase of the sieve stability ratio across all 14 mixes. When the W/B was around 0.33 , the stability risk was clearly evident $\left(f_{u}>098, f>095\right.$ and $\left.\pi<0.15\right)$, and increased when the W/B ratio exceeded $0.41\left(f_{u}<098, f<0.95\right.$ and $\left.\pi>0.15\right)$. The $\mathrm{W} / \mathrm{B}$ is the most significant parameter influencing the rheological properties of concretes. The relationship obtained between W/B and the different stability parameters used, show that this ratio influences them differently (Figure 7). Additionally, these relationships may not all be proportional.

The effect of W/B on the viscosity on the sieve segregation of mixtures is more dominant than other studied parameters. The W/B affects viscosity exponentially, as indicated by Libre et al (2010). The 
effect of the water quantity is also illustrated in Figure 8.

Segregation appeared in all three tests with W/B ratios higher than 0.32 . A decrease of this ratio by $19.51 \%$ (from a W/B of 41 to 33) caused a decrease in the indicators of the segregation $\pi$ (sieve) of $51.33 \%$ and an increase of $f$ and $f_{u}$ to $99.79 \%$ and $17.71 \%$, respectively for the concretes with $20 \%$ fillers (C8, C14). Figure 9 shows the evolution of the three indicators of segregation $\left(f_{u}, \pi\right.$ and $f$ ), with the filler/binder (F/B) ratio similar in both cases. The ultrasonic coefficient $f_{u}$ was less sensitive to the variation of the fines quantity in the concrete than the sieve coefficient $\pi$ and column coefficient $f$, especially for unstable concretes. The variations were respectively, 6.6\% $\left[\left(\mathrm{C} 2, f_{u}=90.70\right)-(\mathrm{C} 8\right.$, $\left.\left.f_{u}=84.10\right)\right], 7.04 \%[(\mathrm{C} 2, \pi=16.49)-(\mathrm{C} 8$, $\pi=23.53)]$, and $16.60 \%[(\mathrm{C} 2, f=64.30)$ - $(\mathrm{C} 8, f=47.70)]$ for a $15.24 \%$ variation of the $\mathrm{F} / \mathrm{B}$ ratio $[(\mathrm{C} 2, \mathrm{~F} / \mathrm{B}=4.76)-(\mathrm{C} 8$, $\mathrm{F} / \mathrm{B}=20)$ ]. This is because UPVs were determined through the concrete (mortar and gravel), whereas the resistance segregation index $f$ related only to gravel. The pulse velocity was affected significantly by the F/B ratio (considering the two concrete groups: unstable and stable). The pulse velocity of the binder pulse was lower than that of the aggregate, but the consistency of paste affected the velocity more than the aggregates when the concrete was stable.

In Figure 10, for the stable mixes the standard deviation (SD) of each segregation test was plotted against the average results. For the column resistance test, at segregation ratios above $95 \%$ (the proposed limit for non-segregating mixes), the average SD was 1.4\% (Figure 10a). For the UPV column resistance test, at segregation ratios above 99\% (the proposed limit for non-segregating mixes), the average standard deviation was $0.28 \%$ (Figure 10b). In general, for all tests SDs were higher in the concrete where segregation was present.

The stable concretes (C9-C14) were those having a sieve segregation index lower than 15\%, (Figures 11 and 12). All of these concretes displayed an ultrasonic index $f_{u}$ in excess of $98 \%$. For these mixes, when the difference of aggregate content in the column $(f)$ did not vary by more than $5 \%$, the segregation ultrasonic index $f_{u}$ did not change by more than $2 \%$. These results demonstrate the efficacy of using (a) Unstable mixes

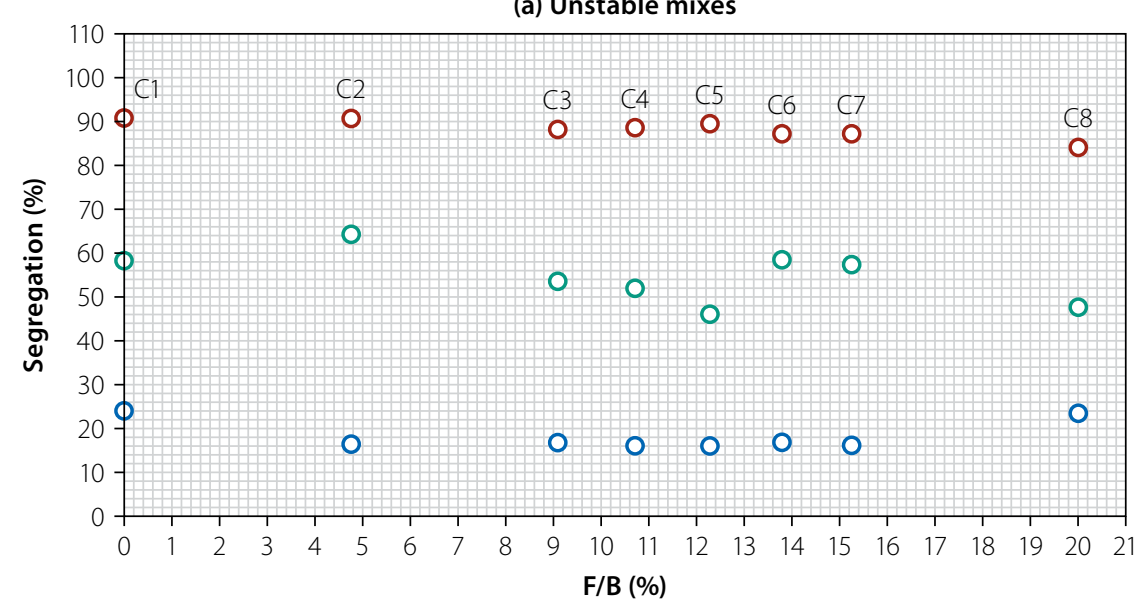

(b) Stable mixes

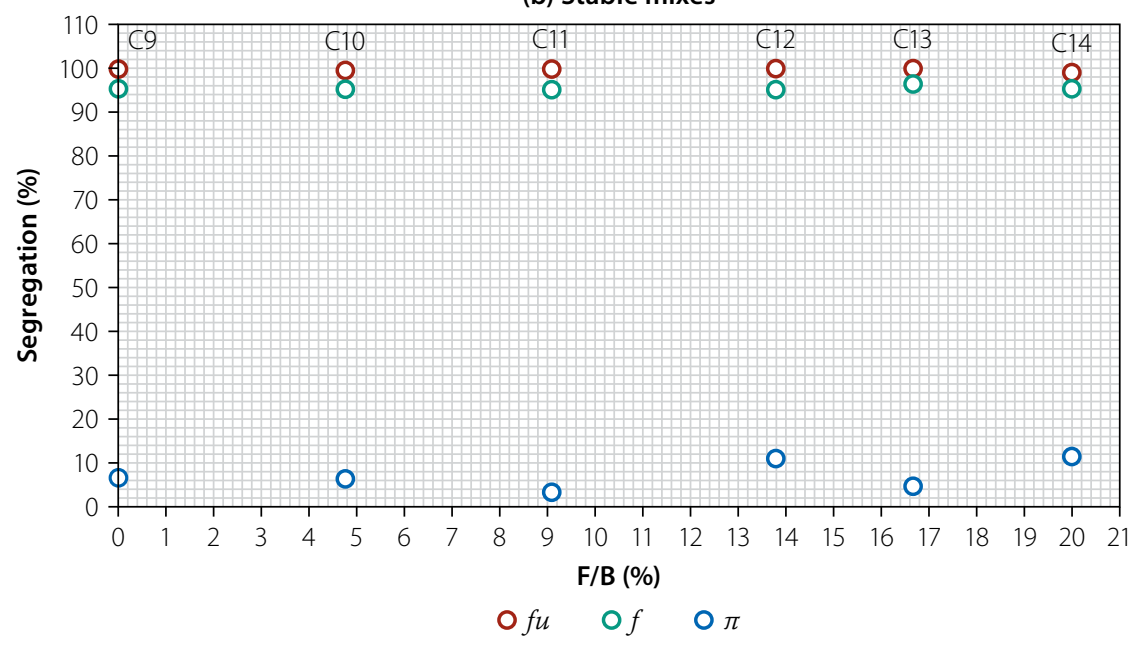

Figure 9 Evolution of the segregation index $\left(f_{u^{\prime}}\right.$, and $\left.\pi\right)$ with F/B ratio: (a) unstable mixes, (b) stable mixes

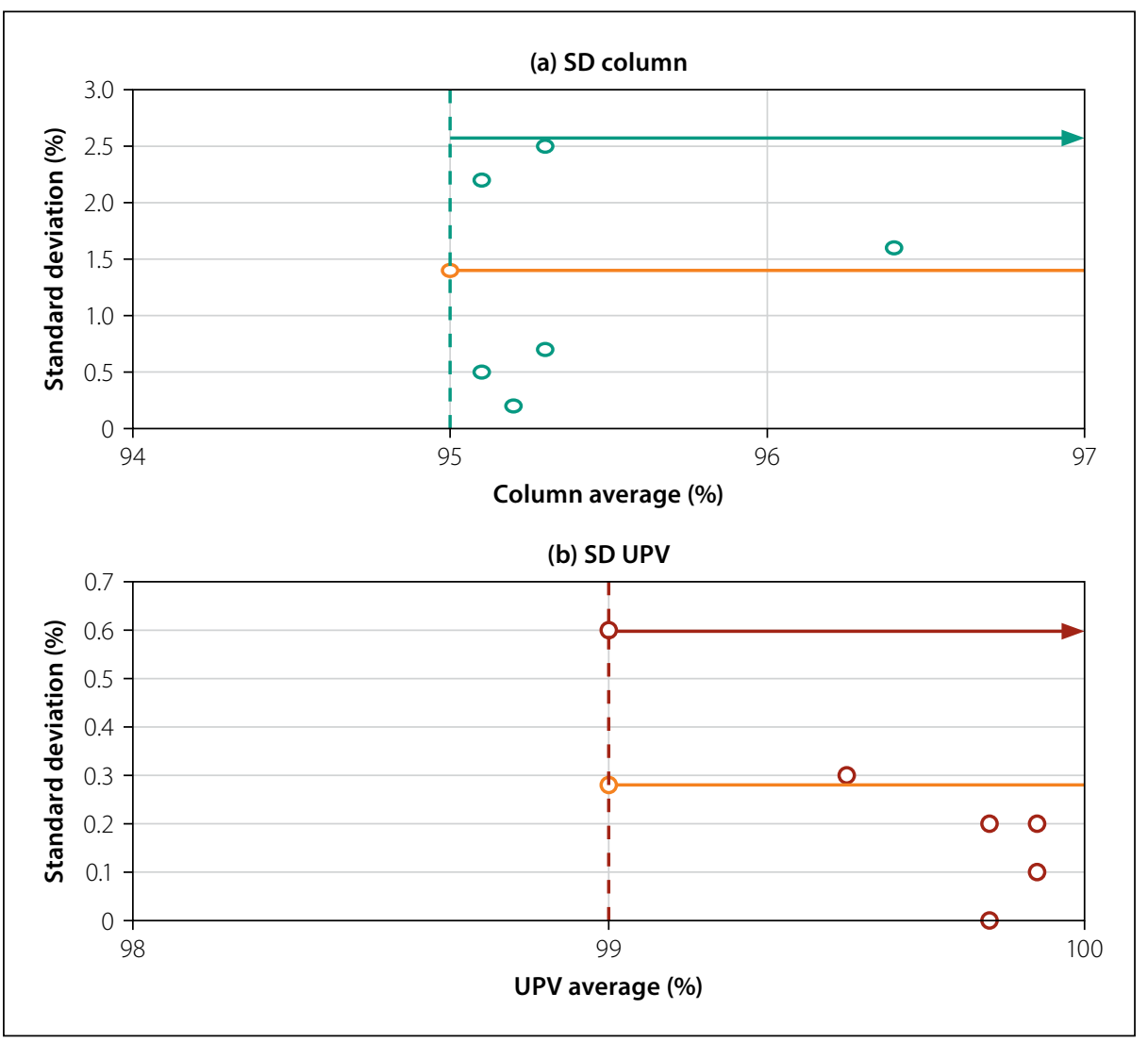

Figure 10 Standard deviation vs average value (for stable concretes): (a) column average, (b) UPV average 


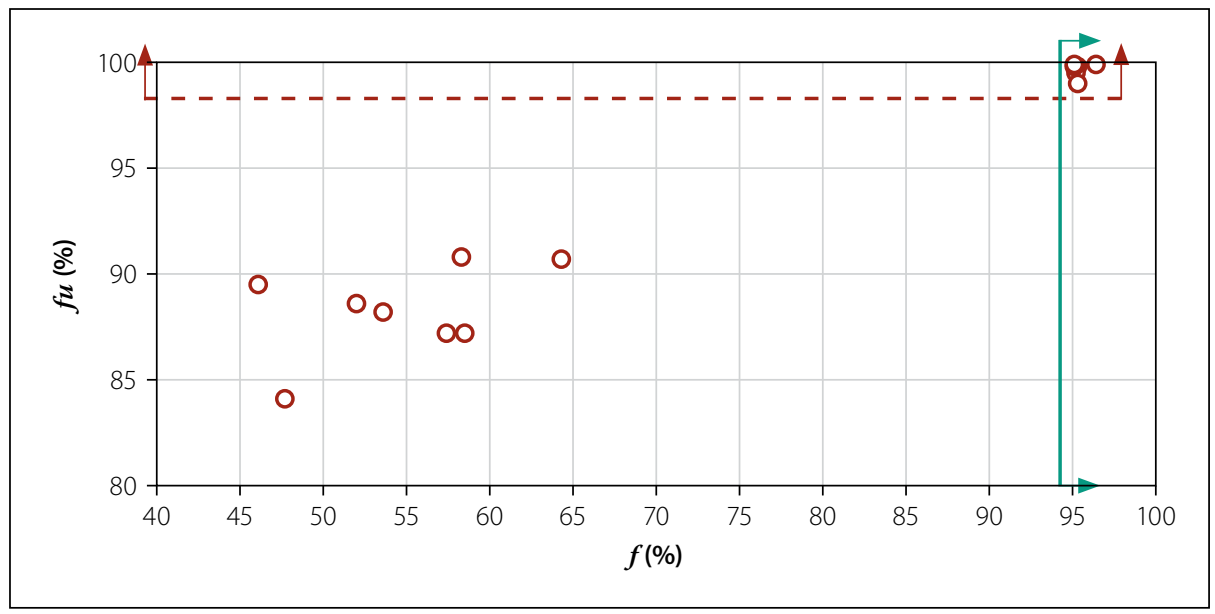

Figure 11 Relations between UPV segregation index $\left(f_{u}\right)$ and column segregation resistance index $(f)$

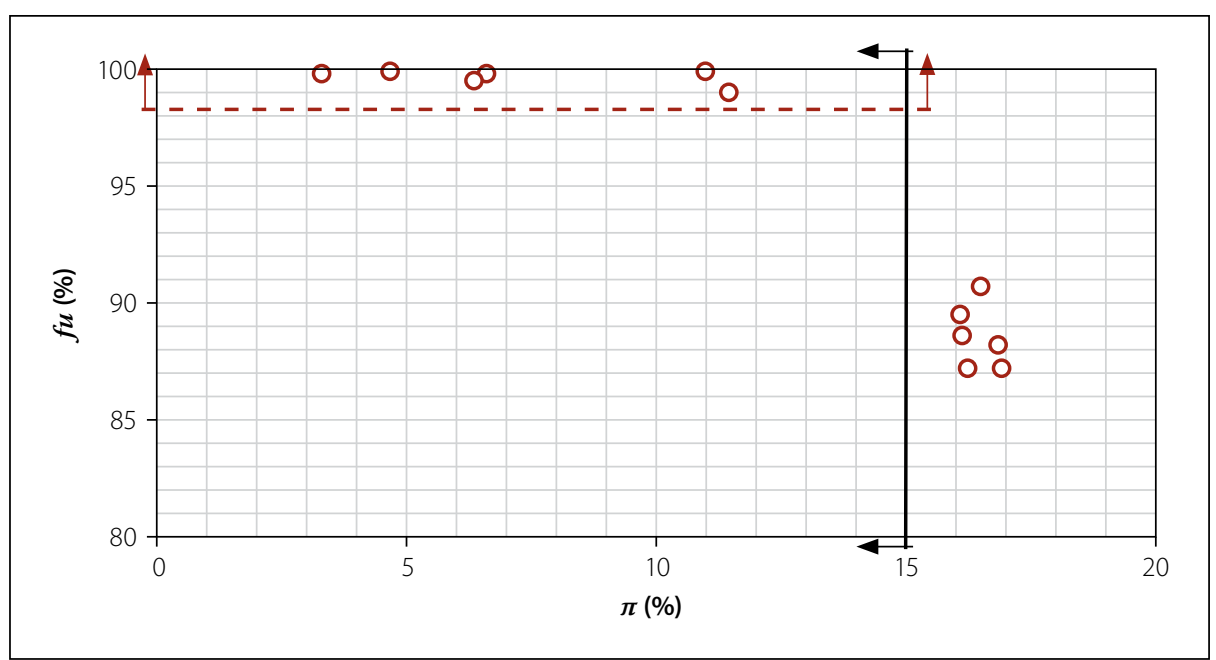

Figure 12 Relations between UPV segregation index $\left(f_{u}\right)$ and sieve stability index $(\pi)$

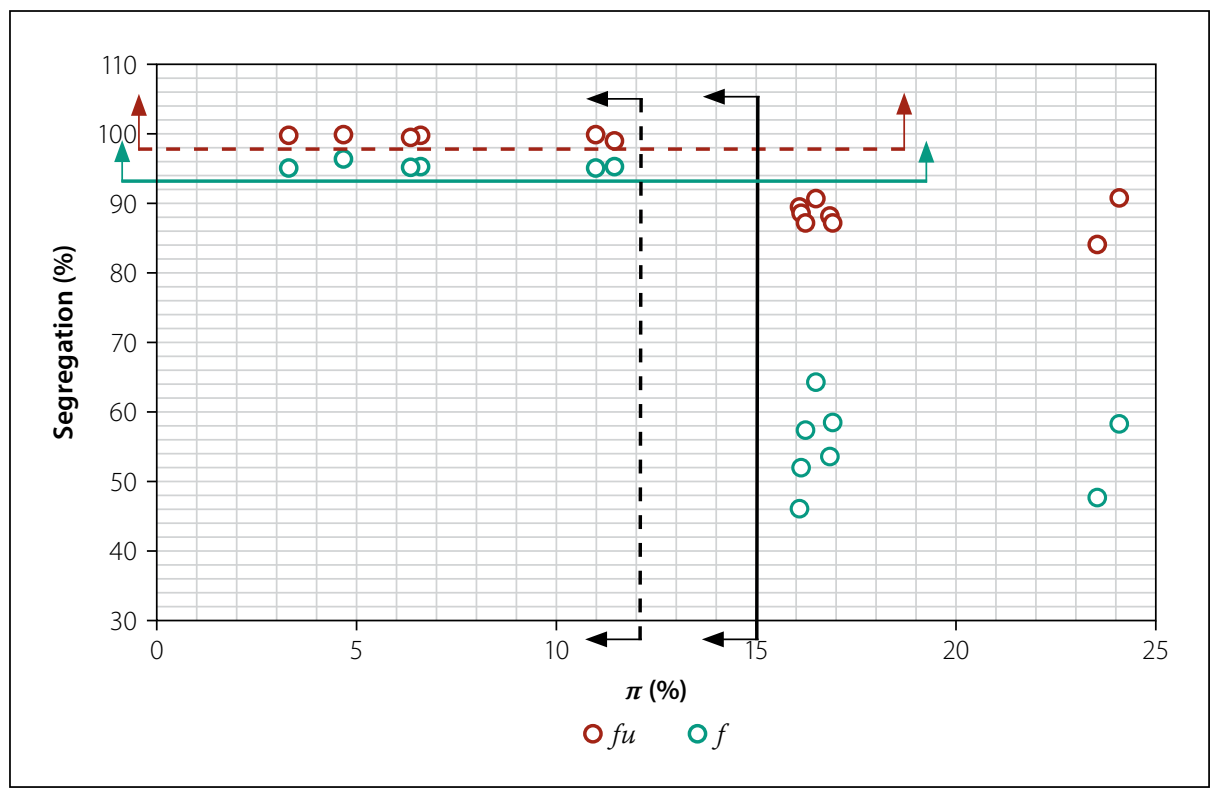

Figure 13 Relations between sieve segregation index $(\pi)$ and segregation resistances index $\left(f_{u}\right.$ and $\left.f\right)$

the ultrasonic pulse velocity method for segregation characterisation in fresh concrete. Therefore, it is necessary to suggest that the sieve stability index $(\pi)$ should be reduced to $12 \%$, while keeping the column segregation resistance index $(f)$ at $95 \%$, and proposing the addition of the homogeneity of the concrete in terms of segregation. Considering the two concrete groups, unstable and stable, a decrease in the W/B ratio led to distinctive increases in the segregation indices $f_{u}, f$ and $\pi$. The ultrasonic segregation index $f_{u}$ was found to be less sensitive to the variation of the fines ratio than the segregation resistance index $f$. This was especially true for unstable mixes. The proportion of water was a major factor in segregation for SCC, as expected. The effect of the F/B ratio showed similar results. This was because the UPVs were determined through the cement paste and granular skeleton (the pulse velocity of binder was lower than that of aggregate), whereas the $f$ index concerns gravel mass only.

The stable concretes (those having a sieve segregation index lower than 15\%) all displayed resistance index $f$ values higher than $95 \%$ and ultrasonic index $f_{u}$ values higher than $99 \%$. In this study, the stable concretes (C9-C14) were highly identifiable regardless of the measuring methods and the water proportions used, but identification was especially easy with the UPV test results, which remained almost constant. The results found by UPV, and those found by traditional sieve and column tests were similar. As such, the usability of non-destructive test methods for evaluation of segregation of concrete was proven. This study showed the possibility to characterise concrete segregation with a clean, rapid, and easyto-use non-destructive method at an acceptable precision and level.

Future work should focus on more precise analyses of how the weight, nature of the gravel (the effect of geometry on the gravel segregation) and shape of the test piece (edge effect), as well as the frequency of the ultrasonic transducers, impact the outputs. Additional work is also needed to compare segregation measurements on fresh SCC with real in-situ segregation.

\section{REFERENCES}

Abdelhalim, B \& Abdelouahab, G 2011. Estimation of concrete's porosity by ultrasound. Physics Procedia, 21: 53-58.

Abdelouahab, G \& Abdelhalim B 2016. Investigation of concrete segregation by ultrasonic pulse velocity. Journal of Architectural Engineering Technology,

5: 169. DOI: 10.4172/2168-9717.1000169.

\section{CONCLUSIONS}

In this experimental study, a nondestructive method was used to diagnose
AFGC (Association Française de Génie Civil) 2000.

Recommandations provisoires sur les bétons 
auto-plaçants, Documents Scientifiques et Techniques. Paris: AFGC.

Ambroise, J, Rols, S \& Péra, J 1999. Self-leveling concrete: Design and properties. Concrete Science and Engineering, 1(3): 140-147.

ASTM International 2009. ASTM C 5972009. Standard Test Method for Pulse Velocity through Concrete. West Conshohocken, PA: ASTM International.

ASTM International 2017. ASTM C1610/C1610M-17 2017. Standard Test Method for Static Segregation of Self-Consolidating Concrete Using Column Technique. West Conshohocken, PA: ASTM International.

Bauchkar, S D \& Chore, H S 2014. Rheological properties of self-consolidating concrete with various mineral admixtures. Structural engineering and mechanics, 51(1): 1-13.

Beaupre, D 1994. Rheology of high performance shotcrete. PhD Thesis, University of British Columbia. Available at: http://hdl.handle. net/2429/6975 [accessed on 17 September 2017].

Benaicha, M, Jalbaud, O, Roguiez, X, Hafidi Alaoui, A \& Burtschell, Y 2015. Prediction of self-compacting concrete homogeneity by ultrasonic velocity. Alexandria Engineering Journal, 54: 1181-1191.

Bensebti, S 2008. Essai de caractérisation expérimentale de la ségrégation verticale des bétons autoplaçants. PhD Thesis, Université de Constantine, Algérie. Available at: http://revue. umc.edu.dz/index.php/b/article/view/205 [accessed on 20 September 2017].

Breul, P, Geoffray, J M \& Haddani, Y 2008. On site concrete segregation estimation using image analysis. Advanced Concrete Technology, 6(1): 171-180.

British Standards Institute 2004. Testing Concrete Part 4: Determination of Ultrasonic Pulse Velocity, BS EN 12504-4. London: British Standards Institution.

British Standard 1986. BS 1881-203:1986. Testing Concrete. Recommendations for Measurement of Velocity of Ultrasonic Pulses in Concrete. London: British Standards Institution.

Bullock, R E \& Whitehurst, E A 1959. Effect of certain variables on pulse velocities through concrete. Highway Research Board Bulletin, 206: 37.

Cussigh, F, Sonebi, M \& De Schutter, G 2003. Project testing of SCC-segregation test methods. Proceedings, 3rd International RILEM Symposium on Self-compacting Concrete, 17-20 August, Reykjavik, pp 311-322.

Daczko, J A 2002. Stability of self-consolidating concrete assumed or ensured? In: Shah S P, Daczko J A \& Lingscheit J N (Eds). Proceedings, 1st North American Conference on the Design and Use of Self-consolidating Concrete, 2-13 November, Chicago, IL, pp 245-252.

De Schutter, G 2005. Guidelines for Testing Fresh Self-compacting Concrete. European Union Growth Contract No. GRD2-2000-30024 - Testing of SCC.
EFNARC (Experts for Specialized Construction and Concrete Systems) 2005. European Guidelines for Self-Compacting Concrete: Specification, Production, and Use. Available at: http://www.efnarc.org/pdf/ SCCGuidelinesMay2005.pdf.

EN (European Standard) 2010. EN 12350-11. Testing Fresh Concrete. Part 11: Self-compacting ConcreteSieve Segregation Test. Pilsen: European Committee for Standardization (CEN).

Ghafoori, N \& Diawara, H 2010. Evaluation of fresh properties of self-consolidating concrete under long transportation time and extreme temperature. Proceedings, 4th North American Conference on the Design and Use of Self-consolidating Concrete, SCC 2010, 26-29 September, Montreal, Canada, pp 139-152.

Grzeszczyk, S \& Podkowa, P 2004. Effect of micro filler on the properties of self-compacting concrete mixture. Proceedings, 19th Scientific Conference “Concrete and Prefabrication", Jadwisin, Poland, pp 257-262.

Hamidian, M, Shariati, A, Khanouki, M M A, Sinaei, H, Toghroli, A \& Nouri, K 2012. Application of Schmidt rebound hammer and ultrasonic pulse velocity techniques for structural health monitoring. Scientific Research and Essays, 7(21): 1997-2001.

Hattori, K 1979. Experiences with Mighty superplasticizer in Japan. In: Superplasticizers in Concrete, Special Publication 62, Farmington Hills, MI: American Concrete Institute (ACI), pp 37-66. Huet, C 1982. Propriétés acoustiques. In: Le béton hydraulique. Paris: Presses de l'École Nationale des Ponts et Chaussées, pp 423-52.

IAEA (International Atomic Energy Agency) 2002. Guidebook on non-destructive testing of concrete structures. Available at: http://www-pub.iaea.org/ $\mathrm{mtcd} /$ publications/pdf/tcs-17_web.pdf.

ISO (International Standards Organization) 2004. ISO1920-7 2004. Testing of concrete. Part 7: Nondestructive Tests on Hardened Concrete. Geneva, Switzerland: ISO.

Job, T \& Harilal, B 2014. Fresh and hardened properties of concrete containing cold bonded aggregates. Advances in Concrete Construction, 2(2): 77-89. Jones, R 1962. Non-Destructive Testing of Concrete. London: Cambridge University Press.

Kaplan, M F 1959. The effects of age and water-tocement ratio upon the relation between ultrasonic pulse velocity and compressive strength of concrete. Magazine of Concrete Research, 11(32): 85.

Khayat, H K \& Guizani, Z 1997. Use of viscositymodifying admixtures to enhance stability of fluid concrete. ACI Materials Journal, 94(4): 332-340.

Khayat, K H \& Feys, D (Eds) 2010. Production and Placement of Self-Consolidating Concrete. (Proceedings of the 4th North American Conference on the Design and Use of Selfconsolidating Concrete, SCC 2010.) Berlin: Springer. Kumavat, H R, Tapkire, G, Patil, P S \& Chitte, C J 2014. Condition assessment of concrete with NDT.
International Journal of Research in Engineering and Technology, 3(9): 63-67.

Kundu, T 2014. Ultrasonic and electromagnetic waves for nondestructive evaluation and structural health monitoring. Proceedings, 1st International Conference on Structural Integrity, 4-7 February, Tucson, AZ, pp 395-405.

Li, B, Duan, Y, Zhang, Y \& Liu, S 2011. Electromagnetic wave absorption properties of cement-based composites filled with porous materials. Materials Design, 32(5): 3017-3020.

Li, L G \& Kwan, A K H 2013. Concrete mix design based on water film thickness and paste film thickness. Cement and Concrete Composites, 39: 33-42.

Libre, N A, Khoshnazar, R \& Shekarchi, M 2010. Relationship between fluidity and stability of selfconsolidating mortar incorporating chemical and mineral admixtures. Construction and Building Materials, 24: 1262-1271.

Lowke, D, Wiegrink, K H \& Schiessl, P 2003. A simple and significant segregation test for SCC. Proceedings, 3rd International RILEM Conference on SCC, Reykjavik, Iceland, pp 356-368.

Malhotra, V M \& Carino, N J 1991. Handbook on Nondestructive Testing of Concrete. Boca Raton, FL: CRC Press.

Mesbah, H A, Yahia, A \& Khayat, K H 2011. Electrical conductivity method to assess static stability of self-consolidating concrete. Cement and Concrete Research, 41: 451-458.

Mouret, M, El Barrak, M, Bascoul, A, Sbartai, M, Picot J 2003. Caractérisation des grandeurs rhéologiques et d'ouvrabilité des pâtes cimentaires en fonction des paramètres de composition. Validation sur béton. Recherche de corrélation multi-échelle. PN BAP 2002 Projet National Bétons Autoplaçants, Groupe 2 Axe 22, Toulouse, France: LMDC (Laboratoire Matériaux et Durabilité Des Constructions).

Naik, T R \& Malhotra, V M 1991. The ultrasonic pulse velocity method. In: Malhotra, V M, \& Carino, N J (Eds). Handbook on Nondestructive Testing of Concrete. Boca Raton, FL: CRC Press.

Okamura, H \& Ouchi, M 2003. Self-compacting concrete. Advanced Concrete Technology, 1(1): 5-15. Panesar, D \& Shindman, B 2012. The effect of segregation on transport and durability properties of self-consolidating concrete. Cement and Concrete Research, 42(2): 252-264.

Popovics, S, Rose, J L \& Popovics, J S 1990. The behavior of ultrasonic pulses in concrete. Cement and Concrete Research, 20: 259.

Rakesh, K 2015. Self-compacted concrete mix design and its comparison with conventional concrete (M-40). Journal of Civil Environmental Engineering, 5(3): 176.

RILEM 1973. Tests on Concrete by the Method of Ultrasonic Testing. RILEM Technical Recommendations. Series: Tests and Measurements, No. 142. 
Rols, S, Ambroise, J \& Péra, J 1999. Effects of different viscosity agents on the properties of self-leveling concrete. Cement and Concrete Research, 29(2): 261-266.

Rooney, M \& Bartos, P J M 2001. Development of the settlement column segregation test for fresh selfcompacting concrete. Proceedings, 2nd International Symposium on Self-Compacting Concrete, Tokyo, Japan, pp 109-116.

Sanish, K B \& Manu, S 2012. Characterization of strength development of concrete the using ultrasonic method. Proceedings, 18th World Conference on Non-destructive Testing, 16-20 April, Durban, South Africa.

Schwendenmann, G 2005. Study of segregation in selfcompacting concrete walls using gamma densitometry. Proceedings, 2nd North American Conference on the Design and Use of Self-consolidating Concrete, 10-12 November, Chicago, IL.
Shindoh, T \& Matsuoka, Y 2003. Development of combination-type self-compacting, concrete and evaluation test methods. Advanced Concrete Technology, 1(1): 26-36.

Sidky, M, Legrand, C \& Barrioulet, M 1981. Influence of the concentration in aggregate and vibration time on internal segregation in fresh concrete. Materials and Structures, 14(83): 367-377.

Silva, P \& Brito, J 2013. Electrical resistivity and capillarity of self-compacting concrete with incorporation of fly ash and limestone filler. Advances in Concrete Construction, 1(1): 65-84.

Sonebi, M 2005. Evaluation of the segregation resistance of fresh self-compacting concrete using different test methods. Proceedings, 1st International Symposium on the Design, Performance and Use of Self-Consolidating Concrete, SCC 2005, Changsha, China, pp 301-308.

Uysal, M, Yilmaz, K \& Ipek, A M 2012. The effect of mineral admixtures on mechanical properties, chloride ion permeability and impermeability of self-compacting concrete. Construction and Building Materials, 27: 263-270.

Vakhshouri, B \& Nejadi, S 2016. Mix design of selfcompacting light-weight concrete. Structural Engineering and Mechanics, 58: 143-161.

Xie, Y, Liu, B, Yin, J \& Zhou, S 2002. Optimum mix parameters of high-strength self-compacting concrete with ultrapulverized fly ash. Cement and Concrete Research, 32: 477-480.

Xiong, G X, Deng, M, Huang, H Q \& Tang, M S 2011. Absorbing and mechanical properties of cementbased composites with nano-titanic oxide absorbent. Advances In Materials Research, 177: 558-561.

Zülfü, Ç, Ulucan, Türk, K \& Karataş, M 2008. Effect of mineral admixtures on the correlation between ultrasonic velocity and compressive strength for self-compacting concrete. Russian Journal of Nondestructive Testing, 44(5): 367-374. 